Article

\title{
Evaluating the Context-Dependent Total-Factor Energy Efficiency of Counties and Cities in Taiwan ${ }^{\dagger}$
}

\author{
Jin-Li Hu ${ }^{1, *(1)}$ and Tzu-Pu Chang ${ }^{2}(\mathbb{D}$
}

check for updates

Citation: Hu, J.-L.; Chang, T.-P. Evaluating the Context-Dependent Total-Factor Energy Efficiency of Counties and Cities in Taiwan.

Energies 2021, 14, 4615. https:// doi.org/10.3390/en14154615

Academic Editor: Vincenzo Bianco

Received: 30 May 2021

Accepted: 24 July 2021

Published: 30 July 2021

Publisher's Note: MDPI stays neutral with regard to jurisdictional claims in published maps and institutional affiliations.

Copyright: (c) 2021 by the authors. Licensee MDPI, Basel, Switzerland. This article is an open access article distributed under the terms and conditions of the Creative Commons Attribution (CC BY) license (https:// creativecommons.org/licenses/by/ $4.0 /)$.
1 Institute of Business and Management, National Yang Ming Chiao Tung University, Hsinchu 300, Taiwan

2 Department of Finance, National Yunlin University of Science and Technology, Yunlin 640, Taiwan; tzupuchang@gmail.com

* Correspondence: jinlihu@nycu.edu.tw

$+\quad$ This paper is an extended version of our paper presented in 2019 OR Society Annual Conference (OR61) held at University of Kent, UK, 3-5 September 2019.

\begin{abstract}
This paper applies the context-dependent total-factor energy efficiency (CD-TFEE) to determine the multi-layer disaggregate energy efficiency frontiers of twenty administrative regions in Taiwan for the year of 2016. The CD-TFEE overcomes the shortcoming of conventional TFEE index that TFEE is not able to find the "closest target" for each inefficient region in the short run. Furthermore, the CD-TFEE scores here deal with four types of energy inputs (electricity for production, electricity for household and non-household lighting, diesel sales, and gasoline sales), illustrating that multi-layer TFEE frontiers for each energy input in the case of Taiwan can be computed. Empirical results indicate that there are three levels of TFEE frontiers for electricity for production and four levels for other types of energy inputs. In addition, New Taipei City, Taipei City, Keelung City, and Penghu County are at the top level of TFEE frontier for all four energy inputs. This paper also demonstrates that the CD-TFEE procedure generates results different from the CD-DEA introduced by Seiford and Zhu (2003).
\end{abstract}

Keywords: context-dependent data envelopment analysis (CD-DEA); frontier level; total-factor energy efficiency (TFEE); directional distance function (DDF); quasi-fixed inputs

\section{Introduction}

With imported energy accounting for 98\% of Taiwan's total energy supply in 2017 [1], the country is heavily dependent on its sources to support economic activities. The efficient use of energy is, hence, an important issue for Taiwan in order to sustain economic development. Moreover, such efficient energy utilization must be effectively implemented at the regional level, in order to achieve economy-wide energy efficiency.

With respect to energy efficiency measurement, one commonly used method is data envelopment analysis (DEA). DEA is a nonparametric linear programming method that has been abundantly applied to evaluate energy and environment performance. For example, Mardani et al. [2], Sueyoshi and Goto [3], and Xu et al. [4] recently reviewed a large number of related literatures and conclude the popularity of DEA in energy efficiency issues. Among related research, $\mathrm{Hu}$ and Wang [5] firstly introduced a new measure, so-called total-factor energy efficiency (TFEE), to evaluate energy efficiency under a total-factor framework.

According to $\mathrm{Yu}$ and $\mathrm{He}$ [6], Hu and Wang's paper is the second most cited papers utilizing DEA to evaluate energy efficiency during 1992-2018, indicating that the concept of TFEE has been widely accepted by scholars worldwide. However, TFEE lacks for searching the practicable input/output targets for inefficient regions in the short run. It means that the efficient frontier made by TFEE only provides a long-run projection, which may not be feasible for inefficient region in the short run. Therefore, an approach that can find the "closest target" is needed from a management perspective. To deal with this issue, Seiford 
and Zhu [7] propose a context-dependent data envelopment analysis (CD-DEA) model that evaluates regions' efficiency scores against a specific context. The essential idea of CD-DEA is to divide all regions into multi-layer frontiers, which are called the evaluation context. Hence, each inefficient region can find its closest target belong to its evaluation context $[8,9]$.

This paper sets up context-dependent total-factor energy efficiency (CD-TFEE) to determine the multiple frontier levels (layers) of Taiwan's administrative regions. It is noted that the technique of CD-TFEE combines the features of CD-DEA by [7] and TFEE by [5]. The multi-layers of efficiency frontiers obtained from CD-TFEE are calculated by a region's efficiency in each kind of energy input, whereas those from CD-DEA are just calculated by overall technical efficiency (OTE). Undoubtedly, a region may have varying efficiency levels under different energy sources, the frontier levels obtained by CDTFEE should not be totally identical to those resulting from CD-DEA. Hence, the research question of this paper is to find the relative position (level/tier) of each administrative region in terms of different types of energy inputs. By doing so, the amounts of optimal energy inputs in the short run can be determined through the closest targets from CD-TFEE.

The contribution of this paper is twofold. First, the previous literature on Taiwan's regional TFEE scores does not take into account the context-dependence concept and only reports the TFEE scores computed from a single efficiency frontier, such as [10-12], etc. Using 23 administrative regions' data in Taiwan, Hu et al. [10] adopt the TFEE approach to calculate the efficient energy-saving ratios for diesel sales, gasoline sales, industrial electricity, and household and commercial electricity. Hu et al. [11] employ the congestion TFEE model to investigate the TFEE efficiency of administrative regions in Taiwan (after regional consolidation). The above literature uses a single-level TFEE frontier to evaluate and compare the TFEE scores of Taiwan's administrative regions. With the CD-TFEE procedure proposed and applied in this present paper, several levels of energy efficiency frontiers can be constructed for each kind of energy input.

Second, to our best knowledge, in terms of energy efficiency, there is no literature that combines TFEE and CD-DEA to discuss the "closest target" issue, except Hu and Chang [13]. Nevertheless, we note that while $\mathrm{Hu}$ and Chang [13] apply the CD-TFEE procedure to administrative regions in mainland China, there is only one energy input, which is total energy consumption, in their DEA model. Here, we take four energy inputs, and for each energy input, there are several levels of TFEE frontiers. To sum up, clustering regions by multi-layer disaggregate energy efficiency frontiers can help us understand more about the relative position of a region with respect to various kinds of energy inputs. Through the levels of disaggregate energy efficiency frontiers, one can find a region's relative position in a specific kind of energy input.

The remainder of the paper is organized as follows. Section 2 illustrates the proposed CD-TFEE procedure and the corresponding linear programming problems. Section 3 presents the empirical results in the case of Taiwan. Section 4 discusses and concludes our study.

\section{Materials and Methods}

The CD-DEA approach can be viewed as an "onion-peeling" approach. Regions can be divided into different levels of efficiency frontiers according to the evaluation context. Seiford and Zhu [7] use the efficiency concept of overall technical efficiency for finding different levels of efficiency frontiers. In order to categorize the regions by their energy efficiency, the efficiency measure of TFEE raised by $\mathrm{Hu}$ and Wang [5] is employed to sub-group regions into different efficiency levels. Hu and Wang [5] define TFEE as that target energy input divided by actual energy input:

$$
\text { TFEE = Target Energy Input/Actual Energy Input }
$$

The target energy input denotes the efficient projection calculated by a DEA model. Notice that the target energy input should be always lower than the actual energy input, indicating that a TFEE score must be between zero and one. Accordingly, a TFEE score 
with unity implies full energy efficiency, whereas a TFEE score with zero means extremely inefficient usage of a certain energy input [14]).

As mentioned by [13], TFEE score is less than or equal to OTE score on the basis of Farrell efficiency, which imposes proportional (radial) adjustments of all inputs. However, this relation between TFEE and OTE may not always hold at using a non-radial adjustment DEA model [13]. In order to have higher discriminative power, this paper computes both CD-TFEE and CD-DEA by using the non-oriented directional distance function (DDF) DEA model with quasi-fixed non-energy inputs [13,15].

\subsection{Procedures of $C D-D E A$ and $C D$-TFEE}

According to [2], the CD-DEA model runs as follows.

(1) Execute the DEA model by using all counties and cities.

(2) Remove the OTE-efficient regions (i.e., OTE $=1$ ) and let the OTE-inefficient regions to determine a new OTE frontier.

(3) Repeat the step (2) to remove the OTE-efficient counties and cities and form the next level of OTE frontier. Terminate this procedure until there is no inefficient county or city at evaluating a particular context.

As mentioned above, the CD-DEA model determines the multi-layer frontiers by their OTE scores obtained from a DEA model. Accordingly, we can replace the concept of OTE with TFEE. Hence, the procedure of CD-TFEE can be defined as follows.

(1) Run the DEA model by using all counties and cities.

(2) Take out the TFEE-efficient counties and cities (i.e., TFEE $=1$ ) and let the TFEEinefficient regions to constitute a new TFEE frontier.

(3) Repeat step (2) to drop the TFEE-efficient regions and form the next level of TFEE frontier. Terminate this procedure until all counties and cities are efficient under a particular evaluation context.

It is straightforward that the CD-TFEE procedure constructs the levels of frontiers based on regions' TFEE scores rather than OTE scores. In addition, as mentioned above, CDTFEE and CD-DEA may present discrepant conclusions because the multi-layer efficiency frontiers are different using these two procedures. We suggest that CD-TFEE should be more meaningful for forming the benchmarks (closest target) of energy efficiency from policymakers' perspectives.

\subsection{Non-Oriented SBM Directional Distance Function (DDF) with Quasi-Fixed Inputs}

Based on the procedures of CD-OTE and CD-TFEE described above, this paper applies the non-oriented Russell-type directional distance function (DDF) model with quasi-fixed non-energy inputs and an undesirable output to compute the efficiency frontiers [16]. The DEA model for region o can be expressed as:

$$
\begin{aligned}
\vec{D}\left(X, Y^{g}\right)= & \max \frac{1}{L+N+1}\left(\sum_{l=1}^{L} \beta_{l}^{e}+\sum_{n=1}^{N} \beta_{n}^{g}+\sum_{j=1}^{J} \beta_{j}^{b}\right) \\
\text { s.t. } & \sum_{k=1}^{K} \lambda_{k} e_{l k} \leq\left(1-\beta_{l}^{e}\right) e_{l o}, \quad l=1,2, \ldots, L \\
& \sum_{k=1}^{K} \lambda_{k} x_{m k} \leq x_{m o}, \quad m=1,2, \ldots, M \\
& \sum_{k=1}^{K} \lambda_{k} y_{n k}^{g} \geq\left(1+\beta_{n}^{g}\right) y_{n o}^{g}, \quad n=1,2, \ldots, N \\
& \sum_{k=1}^{K} \lambda_{k} y_{j k}^{b}=\left(1-\beta_{j}^{b}\right) y_{j o}^{b} \quad j=1,2, \ldots, J \\
& \lambda_{k} \geq 0, \beta_{l}^{e} \geq 0, \beta_{n}^{g} \geq 0, \beta_{j}^{b} \geq 0, k=1,2, \ldots, K .
\end{aligned}
$$

Here, $X, Y^{g}$, and $Y^{b}$ are input, desirable, and undesirable output matrices for all regions, respectively; $\beta_{l}^{e}, \beta_{n}^{g}$, and $\beta_{n}^{b}$ are non-negative vectors no more than $1 ; \lambda$ is a vector 
of peer weights over every region; $e_{l k}$ is the $l$ th energy input for region $k ; e_{l o}$ is the $l$ th energy input for region $o ; x_{m k}$ is the $m$ th non-energy input matrix of all regions; $x_{m o}$ is the $m$ th non-energy input vector for region $o ; y_{n k}^{g}$ is the $n$th desirable output for region $k ; y_{n o}^{g}$ is the $n$th desirable output for region $o ; y_{j k}^{b}$ is the $j$ th undesirable output for region $k ; y_{j o}^{b}$ is the $j$ th desirable output for region $o$. It is worth noting that there are both radial and nonradial slacks in the constraints of energy inputs and outputs, whereas there are no radial and non-radial slack adjustments in the constraint of non-energy inputs. Non-orientation implies that energy inputs are radially contracted, whereas at the same time, outputs are radially expanded.

In this radial Russell-type DDF DEA model with quasi-fixed inputs, energy inputs (e) can be adjusted, whereas all other non-energy inputs (such as labor) are assumed to be quasi-fixed. In other words, energy inputs are the only adjustable inputs in this DEA model to move an inefficient region to the efficiency frontier, hence generating greater discriminative power on TFEE scores $[15,17]$. Similar DEA model setups show up in the book chapter of $\mathrm{Hu}$ and Chang [13] that have only one energy input as adjustable and all non-energy inputs as quasi-fixed. However, there are multiple adjustable energy inputs in this paper, and regions will be sub-grouped into different efficiency frontier levels with respect to different kinds of energy inputs.

We compute the TFEE score with respect to each energy efficiency frontier for each energy input by following the definition in Equation (3):

$$
\mathrm{TFEE}_{l o}=1-\beta_{l}^{e}
$$

In other words, each energy input of region $o$ has its own disaggregate energy efficiency scores.

\section{Results}

\subsection{Data Sources and Variables}

This paper collects annual data from Taiwan's 20 cities and counties in 2016. Note that in 2010, the Taiwan government performed specific mergers of the cities and counties of Kaohsiung, Tainan, and Taichung and renamed Taipei County as New Taipei City. Thus, the number of Taiwan's administrative regions has decreased from 23 to 20. These counties and cities can categorized into five areas in Taiwan: north $(\mathrm{N})$, central $(\mathrm{C})$, south $(\mathrm{S})$, east $(\mathrm{E})$, and outer islands $(\mathrm{O})$. With respect to the evaluation part, we construct five-inputs and two-output DEA model. The first input is total income in the 2016 price level. Total income is measured by multiplying the total number of households and the average family income and from the Directorate-General of Budget, Accounting, and Statistics (DGBAS), Executive Yuan. The second output, PM2.5, is an undesirable output as the annual average concentration, which was obtained from the Environmental Protection Administration.

Five inputs include (1) employed persons, (2) electricity consumed for production, (3) electricity used for household and non-household lighting, (4) gasoline sales, and (5) diesel sales. The number of employed persons of each region is collected from DGBAS. Electricity consumed for production denotes electricity supplied to commerce and industries. Electricity used for household and non-household lighting is defined as electricity supplied to small stores and residences. The data source of these two energy inputs is Taiwan Power Company. The rest of the two energy inputs, diesel and gasoline sales, are obtained from the Bureau of Energy, Ministry of Economic Affairs.

The input/output variable selection in this paper follows the same choice in [10-12], which is also devoted to the research on Taiwan's energy efficiency. The summary statistics and the corresponding units of input and output variables are shown in Table 1. Additionally, Table 2 provides the correlation matrix for all input and output variables in order to detect the isotonicity property, a basic assumption in DEA model. Because all correlation coefficients are positive, this indicates that input and output variables in this paper satisfy the isotonicity property. 
Table 1. Summary of statistics for regional output and input data in Taiwan in 2016.

\begin{tabular}{cccccc}
\hline Variable & Mean & SD & Min. & Max. & Unit \\
\hline Total regional income $\left(\mathrm{y}_{1}\right)$ & $53,394.8$ & $59,141.70$ & 4320.24 & $197,662.15$ & NTD 10 million in 2016 \\
PM2.5 concentration $\left(\mathrm{y}_{2}\right)$ & 19.74 & 5.52 & 9.30 & 28.50 & $\mu \mathrm{mg} / \mathrm{m}^{3}$ \\
Labor employment $\left(\mathrm{x}_{1}\right)$ & 563.35 & 542.42 & 44 & 1947 & $1000 \mathrm{people}$ \\
Electricity for production $\left(\mathrm{x}_{2}\right)$ & $7,426,986.9$ & $7,816,966.05$ & 169,385 & $22,676,281$ & $\mathrm{MWh}$ \\
Electricity for lighting $\left(\mathrm{x}_{3}\right)$ & $3,181,587.2$ & $3,221,694.41$ & 238,022 & $11,139,602$ & $\mathrm{MWh}$ \\
Gasoline sales $\left(\mathrm{x}_{4}\right)$ & 522,889 & $455,881.85$ & $27,017.45$ & $1,434,268.73$ & $1000 \mathrm{~L}$ \\
Diesel sales $\left(\mathrm{x}_{5}\right)$ & 222,618 & $193,918.27$ & $20,859.51$ & $615,220.18$ & $1000 \mathrm{~L}$ \\
\hline
\end{tabular}

Table 2. Correlation matrix of input/output variables.

\begin{tabular}{|c|c|c|c|c|c|c|c|}
\hline Variable & $\begin{array}{l}\text { Total Regional } \\
\text { Income }\end{array}$ & $\begin{array}{l}\text { PM2.5 Con- } \\
\text { centration }\end{array}$ & $\begin{array}{l}\text { Labor Em- } \\
\text { ployment }\end{array}$ & $\begin{array}{l}\text { Electricity for } \\
\text { Production }\end{array}$ & $\begin{array}{l}\text { Electricity for } \\
\text { Lighting }\end{array}$ & $\begin{array}{l}\text { Gasoline } \\
\text { Sales }\end{array}$ & $\begin{array}{c}\text { Diesel } \\
\text { Sales }\end{array}$ \\
\hline $\begin{array}{l}\text { Total regional } \\
\text { income }\end{array}$ & 1.000 & - & - & - & - & - & - \\
\hline $\begin{array}{c}\text { PM2.5 } \\
\text { concentration }\end{array}$ & 0.627 & 1.000 & - & - & - & - & - \\
\hline Labor employment & 0.970 & 0.173 & 1.000 & - & - & - & - \\
\hline $\begin{array}{l}\text { Electricity for } \\
\text { production }\end{array}$ & 0.658 & 0.314 & 0.723 & 1.000 & - & - & - \\
\hline $\begin{array}{l}\text { Electricty for } \\
\text { lighting }\end{array}$ & 0.972 & 0.141 & 0.996 & 0.726 & 1.000 & - & - \\
\hline Gasoline sales & 0.899 & 0.242 & 0.963 & 0.838 & 0.968 & 1.000 & - \\
\hline Diesel sales & 0.679 & 0.332 & 0.801 & 0.872 & 0.801 & 0.914 & 1.000 \\
\hline
\end{tabular}

\subsection{Levels of CD-DEA and CD-TFEE Frontiers}

Taiwan's administrative regions can be categorized into five areas: north $(\mathrm{N})$, central $(\mathrm{C})$, south $(\mathrm{S})$, east $(\mathrm{E})$, and outer islands $(\mathrm{O})$. Tables 3-7 report the frontier levels determined by CD-DEA and CD-TFEE for these regions in 2016, respectively. The numbers in these tables are efficiency scores with respect to each level of efficiency frontiers. For all CD-DEA and CD-TFEE scores in Taiwan, there are three or four levels of efficiency frontiers. Even though the regions on each level of efficiency frontiers of different energy inputs are similar, the TFEE scores vary quite a lot.

Table 3. Multi-level overall technical efficiency frontiers of counties and cities in Taiwan.

\begin{tabular}{ccccccc}
\hline ID & Name & Area & Level 1 & Level 2 & Level 3 & Level 4 \\
\hline 1 & New Taipei City & $\mathrm{N}$ & 1.000 & - & - & - \\
2 & Taipei City & $\mathrm{N}$ & 1.000 & - & - & - \\
3 & Taichung City & $\mathrm{C}$ & 0.471 & 1.000 & - & - \\
4 & Tainan City & $\mathrm{S}$ & 0.428 & 0.733 & 1.000 & - \\
5 & Kaohsiung City & $\mathrm{S}$ & 0.547 & 1.000 & - & - \\
6 & Taoyuan City & $\mathrm{N}$ & 0.498 & 1.000 & - & - \\
7 & Keelung City & $\mathrm{N}$ & 1.000 & & - & - \\
8 & Hsinchu City & $\mathrm{N}$ & 0.510 & 1.000 & - & - \\
9 & Chiayi City & $\mathrm{S}$ & 0.778 & 1.000 & - & - \\
10 & Yilan County & $\mathrm{N}$ & 0.457 & 1.000 & - & - \\
11 & Hsinchu County & $\mathrm{N}$ & 0.430 & 0.775 & 1.000 & - \\
12 & Miaoli County & $\mathrm{C}$ & 0.405 & 0.658 & 0.899 & 1.000 \\
13 & Changhua County & $\mathrm{C}$ & 0.398 & 0.697 & 1.000 & - \\
14 & Nantou County & $\mathrm{C}$ & 0.429 & 0.810 & 1.000 & - \\
15 & Yunlin County & $\mathrm{C}$ & 0.384 & 0.643 & 0.841 & 1.000 \\
16 & Chiayi County & $\mathrm{S}$ & 0.437 & 0.817 & 1.000 & - \\
17 & Pingtung County & $\mathrm{S}$ & 0.441 & 1.000 & - & - \\
18 & Taitung County & $\mathrm{E}$ & 0.480 & 1.000 & - & - \\
19 & Hualien County & $\mathrm{E}$ & 0.424 & 0.833 & 1.000 & - \\
20 & Penghu County & $\mathrm{O}$ & 1.000 & - & - & - \\
\hline
\end{tabular}

Note: N: north; C: central; W: west; E: east; O: outer islands. 
Table 4. Multi-level efficiency frontiers of electricity for production of counties and cities in Taiwan.

\begin{tabular}{cccccc}
\hline ID & Name & Area & Level 1 & Level 2 & Level 3 \\
\hline 1 & New Taipei City & $\mathrm{N}$ & 1.000 & - & - \\
2 & Taipei City & $\mathrm{N}$ & 1.000 & - & - \\
3 & Taichung City & $\mathrm{C}$ & 0.299 & 1.000 & - \\
4 & Tainan City & $\mathrm{S}$ & 0.175 & 0.595 & 1.000 \\
5 & Kaohsiung City & $\mathrm{S}$ & 0.294 & 1.000 & - \\
6 & Taoyuan City & $\mathrm{N}$ & 0.235 & 1.000 & - \\
7 & Keelung City & $\mathrm{N}$ & 1.000 & - & - \\
8 & Hsinchu City & $\mathrm{N}$ & 0.144 & 1.000 & - \\
9 & Chiayi City & $\mathrm{S}$ & 1.000 & - & - \\
10 & Yilan County & $\mathrm{N}$ & 0.437 & 1.000 & - \\
11 & Hsinchu County & $\mathrm{N}$ & 0.173 & 0.769 & 1.000 \\
12 & Miaoli County & $\mathrm{C}$ & 0.196 & 0.667 & 1.000 \\
13 & Changhua County & $\mathrm{C}$ & 0.275 & 0.933 & 1.000 \\
14 & Nantou County & $\mathrm{C}$ & 0.523 & 1.000 & - \\
15 & Yunlin County & $\mathrm{C}$ & 0.291 & 0.990 & 1.000 \\
16 & Chiayi County & $\mathrm{S}$ & 0.542 & 1.000 & - \\
17 & Pingtung County & $\mathrm{S}$ & 0.544 & 1.000 & - \\
18 & Taitung County & $\mathrm{E}$ & 0.858 & 1.000 & - \\
19 & Hualien County & $\mathrm{E}$ & 0.387 & 1.000 & - \\
20 & Penghu County & $\mathrm{O}$ & 1.000 & - & - \\
\hline
\end{tabular}

Note: N: north; C: central; W: west; E: east; O: outer islands.

Table 5. Multi-level efficiency frontiers of electricity for lighting of cities and counties in Taiwan.

\begin{tabular}{ccccccc}
\hline ID & Name & Area & Level 1 & Level 2 & Level 3 & Level 4 \\
\hline 1 & New Taipei City & N & 1.000 & - & - & - \\
2 & Taipei City & N & 1.000 & - & - & - \\
3 & Taichung City & $\mathrm{C}$ & 0.579 & 1.000 & & - \\
4 & Tainan City & $\mathrm{S}$ & 0.645 & 0.817 & 1.000 & - \\
5 & Kaohsiung City & $\mathrm{S}$ & 0.789 & 1.000 & - & - \\
6 & Taoyuan City & $\mathrm{N}$ & 0.742 & 1.000 & - & - \\
7 & Keelung City & $\mathrm{N}$ & 1.000 & - & - & - \\
8 & Hsinchu City & $\mathrm{N}$ & 0.871 & 1.000 & - & - \\
9 & Chiayi City & $\mathrm{S}$ & 0.783 & 1.000 & - & - \\
10 & Yilan County & $\mathrm{N}$ & 0.668 & 1.000 & - & - \\
11 & Hsinchu County & $\mathrm{N}$ & 0.770 & 0.948 & 1.000 & - \\
12 & Miaoli County & $\mathrm{C}$ & 0.701 & 0.888 & 1.000 & - \\
13 & Changhua County & $\mathrm{C}$ & 0.522 & 0.661 & 1.000 & - \\
14 & Nantou County & $\mathrm{C}$ & 0.631 & 0.864 & 1.000 & - \\
15 & Yunlin County & $\mathrm{C}$ & 0.568 & 0.719 & 0.963 & 1.000 \\
16 & Chiayi County & $\mathrm{S}$ & 0.635 & 0.873 & 1.000 & - \\
17 & Pingtung County & $\mathrm{S}$ & 0.570 & 1.000 & - & - \\
18 & Taitung County & $\mathrm{E}$ & 0.558 & 1.000 & - & - \\
19 & Hualien County & $\mathrm{E}$ & 0.590 & 0.780 & 1.000 & - \\
20 & Penghu County & $\mathrm{O}$ & 1.000 & - & - & - \\
\hline Note: N: north: C: central: W: west: E: east: O: outer islands. & & &
\end{tabular}

Note: N: north; C: central; W: west; E: east; O: outer islands.

Table 6. Multi-level efficiency frontiers of gasoline of counties and cities in Taiwan.

\begin{tabular}{ccccccc}
\hline ID & Name & Area & Level 1 & Level 2 & Level 3 & Level 4 \\
\hline 1 & New Taipei City & N & 1.000 & - & - & - \\
2 & Taipei City & N & 1.000 & - & - & - \\
3 & Taichung City & C & 0.391 & 1.000 & - & - \\
4 & Tainan City & S & 0.384 & 0.661 & 1.000 & - \\
5 & Kaohsiung City & S & 0.580 & 1.000 & - & - \\
6 & Taoyuan City & N & 0.447 & 1.000 & - & - \\
7 & Keelung City & N & 1.000 & - & - & - \\
\hline
\end{tabular}


Table 6. Cont.

\begin{tabular}{ccccccc}
\hline ID & Name & Area & Level 1 & Level 2 & Level 3 & Level 4 \\
\hline 8 & Hsinchu City & $\mathrm{N}$ & 0.572 & 1.000 & - & - \\
9 & Chiayi City & $\mathrm{S}$ & 0.677 & 1.000 & - & - \\
10 & Yilan County & $\mathrm{N}$ & 0.414 & 1.000 & - & - \\
11 & Hsinchu County & $\mathrm{N}$ & 0.376 & 0.651 & 1.000 & 1.000 \\
12 & Miaoli County & $\mathrm{C}$ & 0.351 & 0.605 & 0.923 & - \\
13 & Changhua County & $\mathrm{C}$ & 0.355 & 0.611 & 1.000 & - \\
14 & Nantou County & $\mathrm{C}$ & 0.283 & 0.581 & 1.000 & 1.000 \\
15 & Yunlin County & $\mathrm{C}$ & 0.312 & 0.538 & 0.800 & - \\
16 & Chiayi County & $\mathrm{S}$ & 0.319 & 0.659 & 1.000 & - \\
17 & Pingtung County & $\mathrm{S}$ & 0.325 & 1.000 & - & - \\
18 & Taitung County & $\mathrm{E}$ & 0.324 & 1.000 & - & - \\
19 & Hualien County & $\mathrm{E}$ & 0.391 & 0.744 & 1.000 & - \\
20 & Penghu County & O & 1.000 & - & & - \\
\hline
\end{tabular}

Note: N: north; C: central; W: west; E: east; O: outer islands.

Table 7. Multi-level efficiency frontiers of diesel of counties and cities in Taiwan.

\begin{tabular}{ccccccc}
\hline ID & Name & Area & Level 1 & Level 2 & Level 3 & Level 4 \\
\hline 1 & New Taipei City & $\mathrm{N}$ & 1.000 & - & - & - \\
2 & Taipei City & $\mathrm{N}$ & 1.000 & - & - & - \\
3 & Taichung City & $\mathrm{C}$ & 0.117 & 1.000 & - & - \\
4 & Tainan City & $\mathrm{S}$ & 0.119 & 0.810 & 1.000 & - \\
5 & Kaohsiung City & $\mathrm{S}$ & 0.147 & 1.000 & - & - \\
6 & Taoyuan City & $\mathrm{N}$ & 0.116 & 1.000 & - & - \\
7 & Keelung City & $\mathrm{N}$ & 1.000 & - & - & - \\
8 & Hsinchu City & $\mathrm{N}$ & 0.361 & 1.000 & - & - \\
9 & Chiayi City & $\mathrm{S}$ & 0.908 & 1.000 & - & - \\
10 & Yilan County & $\mathrm{N}$ & 0.094 & 1.000 & - & - \\
11 & Hsinchu County & $\mathrm{N}$ & 0.133 & 0.747 & 1.000 & - \\
12 & Miaoli County & $\mathrm{C}$ & 0.086 & 0.587 & 0.747 & 1.000 \\
13 & Changhua County & $\mathrm{C}$ & 0.101 & 0.685 & 1.000 & - \\
14 & Nantou County & $\mathrm{C}$ & 0.078 & 0.451 & 1.000 & - \\
15 & Yunlin County & $\mathrm{C}$ & 0.069 & 0.471 & 0.850 & 1.000 \\
16 & Chiayi County & $\mathrm{S}$ & 0.071 & 0.403 & 1.000 & - \\
17 & Pingtung County & $\mathrm{S}$ & 0.076 & 1.000 & - & - \\
18 & Taitung County & $\mathrm{E}$ & 0.079 & 1.000 & - & - \\
19 & Hualien County & $\mathrm{E}$ & 0.081 & 0.507 & 1.000 & - \\
20 & Penghu County & $\mathrm{O}$ & 1.000 & - & - & - \\
\hline
\end{tabular}

Note: N: north; C: central; W: west; E: east; O: outer islands.

Table 3 reports the levels of overall technical efficiency frontiers. New Taipei City $(\mathrm{N})$, Taipei City $(\mathrm{N})$, Keelung City $(\mathrm{N})$, and Penghu County $(\mathrm{O})$ are on the level 1 (with highest efficiency) OTE frontier. There is no northern region on the 4th (least efficient) OTE level. On the 4th OTE level, there are two central regions. The northern area is the richest with the highest metropolitan density and unit value added in Taiwan.

Table 4 reports the levels of efficiency frontiers of electricity for production. New Taipei City (N), Taipei City (N), Keelung City (N), Chiayi City (S), and Penghu County (O) are the five regions on the first level of electricity for production efficiency frontier. Notice that there three levels of efficiency frontiers with respect to electricity for production. This number is less than other three types of energy inputs, meaning that all regions use electricity for production more efficiently in comparison to other energy sources. Tainan County (S), Miaoli County (C), Changhua County (C), and Yunlin County (C) are on the 3rd level (with lowest efficiency), whereas Tainan County and Changhua County are not the worst performer in terms of OTE. This result confirms that the CD-TFEE approach can present a higher discriminative power in a DEA model. 
Table 5 reports the levels of electricity for lighting efficiency frontiers. New Taipei City (N), Taipei City (N), Keelung City (N), Chiayi City (S), and Penghu County (O) are the five regions on the top level of lighting electricity efficiency frontiers. There is no northern region on the 4 th (least efficient) level. Yunlin County (C), which is in the central area, is the only one region on the 4 th lighting electricity efficiency level.

Table 6 shows the levels of gasoline efficiency frontiers. Similar to Table 5, New Taipei City (N), Taipei City (N), Keelung City (N), and Penghu County (O) are at the top level of gasoline efficiency frontiers. There is no northern region on the 4 th (lowest energy efficiency) level. On the 4th level of gasoline efficiency frontiers, there are two central regions-Miaoli County and Yunlin County.

Table 7 presents the levels of diesel efficiency frontiers. New Taipei City (N), Taipei City (N), Keelung City (N), and Penghu County (O) are on the level 1 of diesel TFEE frontier. It is noted that the average scores of the first level is lower than those of other inputs, implying that Taiwan's regions use diesel inefficiently relative to other energy sources. There is no northern region on the 4th (least efficient) level. On the 4th diesel efficiency level, there are two central regions-Miaoli County and Yunlin County. It is noteworthy that the efficiency scores of the first level show a substantial dispersion among 20 regions, indicating that the technology gap between the top and second level frontiers is remarkable in comparison to the other three inputs. We suggest that the key determinant is transportation system. Except for Penghu County in the outer islands, New Taipei City, Taipei City, and Keelung City are commonly known as the Greater Taipei Metropolitan Area, which is the largest metropolitan area in Taiwan. The transportation system of this area is served by Taiwan Railway, Taiwan High Speed Rail, Taipei Metro, and an extensive bus system. Hence, these cities can efficiently consume diesel input. Accordingly, other local governments should reconsider their transportation policies in order to catch up the 1st diesel efficiency frontier.

From the above discussion, we find that Taiwan has a high disparity in energy efficiency levels. There are only four regions on the level 1 energy efficiency frontiers for all four kinds of energy inputs. The northern and outer island areas are the most energyefficient among all five areas, whereas the central area has the largest room for improvement in various kinds of energy efficiency.

With respect to the issue of closest target aforementioned, Table 8 presents the saving targets (i.e., actual input minus target input) for each kind of energy input based on TFEE and CD-TFEE models. As Table 8 indicates, on average, the saving target of electricity for production is much higher than the other three inputs because it is a main energy input for economic value creation. For electricity for production, the CD-TFEE saving targets of six regions (Tainan City, Hsinchu County, Miaoli County, Changhua County, and Yunlin County) greatly differ from the TFEE saving targets of them. For example, Yunlin County has to reduce electricity for production with 2,705,784 MWh in order to reach the TFEE efficient frontier, while only 38,726 MWh need to be cut in order to approach the closest frontier based on CD-TFEE method. This finding also reveals that inefficient regions may adjust their energy inputs to reach the TFEE frontier because CD-TFEE can provide a feasible target in the short run.

A similar pattern is found in terms of other three energy inputs. For these three inputs, nine counties and cities present huge gaps between the CD-TFEE and the TFEE saving targets, especially for Miaoli County and Yunlin County. It means that counties and cities on the lower level (less efficiency) result in larger differences between the CD-TFEE and the TFEE saving targets. To sum up, from a methodology perspective, the CD-TFEE approach constructs multi-layer TFEE efficient frontiers, which find the closest target for each inefficient DMU on the corresponding frontier. Moreover, from an administrative perspective, each local government would understand its relative position (level/tier) in the usage of each energy input. For instance, assuming that there is no technology progress, the policymakers of Yunlin County should establish transportation policies and reduce 
30,604, 108,112, and 190,375 (thousand liters) diesel sales to catch up the 3rd (short-run), 2nd, and 1st (long-run) level of efficiency frontiers of diesel, respectively.

Table 8. Energy saving targets obtained from CD-TFEE and TFEE models.

\begin{tabular}{|c|c|c|c|c|c|c|c|c|}
\hline & \multicolumn{4}{|c|}{ TFEE Saving Targets } & \multicolumn{4}{|c|}{ CD-TFEE Saving Targets } \\
\hline & $\begin{array}{l}\text { Electricity for } \\
\text { Production } \\
\text { (MWh) }\end{array}$ & $\begin{array}{l}\text { Electricity for } \\
\text { Lighting } \\
\text { (MWh) }\end{array}$ & $\begin{array}{l}\text { Gasoline } \\
\text { (1000 L) }\end{array}$ & $\begin{array}{c}\text { Diesel } \\
(1000 \text { L) }\end{array}$ & $\begin{array}{l}\text { Electricity for } \\
\text { Production } \\
\text { (MWh) }\end{array}$ & $\begin{array}{l}\text { Electricity for } \\
\text { Lighting } \\
\text { (MWh) }\end{array}$ & $\begin{array}{l}\text { Gasoline } \\
\text { (1000 L) }\end{array}$ & $\begin{array}{c}\text { Diesel } \\
(1000 \text { L) }\end{array}$ \\
\hline New Taipei City & 0 & 0 & 0 & 0 & 0 & 0 & 0 & 0 \\
\hline Taipei City & 0 & 0 & 0 & 0 & 0 & 0 & 0 & 0 \\
\hline Taichung City & $13,258,568$ & $3,548,675$ & 859,180 & 543,071 & $13,258,568$ & $3,548,675$ & 859,180 & 543,071 \\
\hline Tainan City & $17,702,925$ & $1,780,701$ & 588,648 & 354,170 & $8,699,248$ * & 917,091 * & $323,483 *$ & 76,462 * \\
\hline Kaohsiung City & $16,006,033$ & $1,535,260$ & 471,388 & 493,688 & $16,006,033$ & $1,535,260$ & 471,388 & 493,688 \\
\hline Taoyuan City & $17,074,972$ & $1,579,727$ & 634,837 & 511,638 & $17,074,972$ & $1,579,727$ & 634,837 & 511,638 \\
\hline Keelung City & 0 & 0 & 0 & 0 & 0 & 0 & 0 & 0 \\
\hline Hsinchu City & $7,698,370$ & 165,779 & 95,115 & 29,280 & $7,698,370$ & 165,779 & 95,115 & 29,280 \\
\hline Chiayi City & 0 & 160,008 & 42,853 & 3429 & 0 & 160,008 & 42,853 & 3429 \\
\hline Yilan County & $1,206,463$ & 400,734 & 129,193 & 114,977 & $1,206,463$ & 400,734 & 129,193 & 114,977 \\
\hline Hsinchu County & $6,449,754$ & 347,527 & 218,872 & 111,862 & $1,800,292$ * & $78,009 *$ & $122,495^{*}$ & $32,598 *$ \\
\hline Miaoli County & $4,623,623$ & 415,200 & 203,730 & 152,565 & $1,914,661$ * & 155,363 * & 24,042 * & 42,259 * \\
\hline Changhua County & $5,242,621$ & $1,570,190$ & 352,528 & 226,171 & $481,879 *$ & $1,113,552 *$ & $212,321 *$ & $79,331 *$ \\
\hline Nantou County & 767,544 & 424,907 & 208,556 & 126,289 & 767,544 & $157,142 *$ & 121,976 * & 75,283 * \\
\hline Yunlin County & $2,705,784$ & 729,573 & 238,882 & 190,375 & $38,726^{*}$ & $61,943 *$ & $69,608 *$ & 30,604 * \\
\hline Chiayi County & 713,695 & 418,560 & 176,601 & 141,799 & 713,695 & 146,363 * & $88,445 *$ & 91,103 * \\
\hline Pingtung County & $1,125,635$ & 873,294 & 272,471 & 207,167 & $1,125,635$ & 873,294 & 272,471 & 207,167 \\
\hline Taitung County & 57,270 & 237,636 & 70,850 & 51,366 & 57,270 & 237,636 & 70,850 & 51,366 \\
\hline Hualien County & 970,755 & 368,572 & 93,449 & 88,203 & 970,755 & 197,777 * & 39,261 * & 47,325 * \\
\hline Penghu County & 0 & 0 & 0 & 0 & 0 & 0 & 0 & 0 \\
\hline
\end{tabular}

Note: * denotes that CD-TFEE saving targets differ from TFEE saving targets.

\section{Discussion and Conclusions}

This paper employs the CD-TFEE procedure to sort cities and counties in Taiwan into multiple frontier levels for each type of energy input. As Section 3.2 indicates, the CD-TFEE approach can present more detailed results in comparison to conventional CDDEA. Specifically, there are three to four layers of TFEE frontiers for three types of energy inputs, i.e., diesel sales, gasoline sales, and household and non-household lighting. With respect to electricity for production, three levels of efficiency frontiers are found in this paper. Moreover, New Taipei City (N), Taipei City (N), Keelung City (N), and Penghu County $(\mathrm{O})$ are the four regions always on the top level frontier for each energy input. Yet, the result shows that the regions in southern, eastern, and central areas are inefficient with respect to each kind of energy input. Among them, the central area presents the largest space for improvement in all four kinds of energy inputs.

In summary, even with the existing technology levels, there is still much room for Taiwan to improve its energy efficiency with respect to various kinds of energy inputs. The regional disparity in energy efficiency scores also reflects the imbalance of regional development in Taiwan. Taiwan has been heavily relying on imported energy, which is risky to its economic security. Improving energy efficiency helps Taiwan produce more economic values, given these imported energy sources. In terms of future research, the CD-TFEE approach can be applied to sectors or regions in other economies. It is suggested that TFEE can find better benchmarks for a region to understand its relative energy efficiency positioning.

Author Contributions: Conceptualization, J.-L.H. and T.-P.C.; methodology, J.-L.H.; software, T.-P.C.; validation, J.-L.H.; formal analysis, J.-L.H. and T.-P.C.; investigation, J.-L.H. and T.-P.C.; resources, J.-L.H.; data curation, J.-L.H. and T.-P.C.; writing—original draft preparation, J.-L.H.; writing-review and editing, J.-L.H. and T.-P.C.; visualization, T.-P.C.; supervision, J.-L.H.; project administration, J.-L.H. Both authors have read and agreed to the published version of the manuscript.

Funding: The first and second authors thank financial support from Taiwan's Ministry of Science and Technology (MOST106-2410-H-009-047 and MOST109-2410-H-224-015).

Institutional Review Board Statement: Not applicable.

Informed Consent Statement: Not applicable. 
Data Availability Statement: The data presented in this study are available on request from the corresponding author.

Conflicts of Interest: The authors declare no conflict of interest.

\section{References}

1. Bureau of Energy, Ministry of Economic Affairs, Taiwan. Energy Statistical Annual Reports, Taipei. 2018. Available online: https:/ / www.moeaboe.gov.tw/ECW/english/content/ContentLink.aspx?menu_id=1540 (accessed on 7 July 2018).

2. Mardani, A.; Streimikiene, D.; Balezentis, T.; Saman, M.; Nor, K.; Khoshnava, S. Data Envelopment Analysis in Energy and Environmental Economics: An Overview of the State-of-the-Art and Recent Development Trends. Energies 2018, 11, 2002. [CrossRef]

3. Sueyoshi, T.; Goto, M. Performance Assessment of Japanese Electric Power Industry: DEA Measurement with Future Impreciseness. Energies 2020, 13, 490. [CrossRef]

4. Xu, T.; You, J.; Li, H.; Shao, L. Energy Efficiency Evaluation Based on Data Envelopment Analysis: A Literature Review. Energies 2020, 13, 3548. [CrossRef]

5. Hu, J.L.; Wang, S.C. Total-Factor Energy Efficiency of Regions in China. Energy Policy 2006, 34, 3206-3217. [CrossRef]

6. Yu, D.; He, X. A Bibliometric Study for DEA Applied to Energy Efficiency: Trends and Future Challenges. Appl. Energy 2020, 268, 115048. [CrossRef]

7. Seiford, L.M.; Zhu, J. Context-dependent Data Envelopment Analysis Measuring Attractiveness and Progress. Omega 2003, 31, 397-408. [CrossRef]

8. Morita, H.; Hirokawa, K.; Zhu, J. A Slack-Based Measure of Efficiency in Context-Dependent Data Envelopment Analysis. Omega 2005, 33, 357-362. [CrossRef]

9. $\quad \mathrm{Wu}$, J.; Yu, Y.; Zhu, Q.; An, Q.; Liang, L. Closest Target for the Orientation-Free Context-Dependent DEA under Variable Returns to Scale. J. Oper. Res. Soc. 2018, 69, 1819-1833. [CrossRef]

10. Hu, J.L.; Lio, M.C.; Kao, C.H.; Lin, Y.L. Total-factor Energy Efficiency for Regions in Taiwan. Energy Sources Part B 2012, 7, 292-300. [CrossRef]

11. Hu, J.L.; Chang, M.C.; Tsay, H.W. The Congestion Total-factor Energy Efficiency of Regions in Taiwan. Energy Policy 2017, 110, 710-718. [CrossRef]

12. Hu, J.L.; Chang, M.C.; Tsay, H.W. Disaggregate Energy Efficiency of Regions in Taiwan. Manag. Environ. Qual. 2018, 29, 34-48. [CrossRef]

13. Hu, J.L.; Chang, T.P. The Context-Dependent Total-factor Energy Efficiency of China's Regions. In Energy, Environment and Transitional Green Growth in China; Pang, R., Bai, X., Lovell, C.A.K., Eds.; Springer: Singapore, 2018; pp. $177-187$.

14. Hu, J.L.; Chang, T.P. Total-factor Energy Efficiency and Its Extensions: Introduction, Computation and Application. In Data Envelopment Analysis: A Handbook of Empirical Studies and Applications; Zhu, J., Ed.; Springer: New York, NY, USA, 2016; pp. 45-69.

15. Chang, M.C. A Comment on the Calculation of the Total-factor Energy Efficiency (TFEE) Index. Energy Policy 2013, 53, 500-504. [CrossRef]

16. Sickles, R.C.; Zelenyuk, V. Measurement of Productivity and Efficiency; Cambridge University Press: Cambridge, UK, 2019; pp. 59-95.

17. Ouellette, P.; Vierstraete, V. Technological Change and Efficiency in the Presence of Quasi-fixed Inputs: A DEA Application to the Hospital Sector. Eur. J. Oper. Res. 2004, 154, 755-763. [CrossRef] 